\title{
A terapia comunitária como um novo instrumento de cuidado para saúde mental do idoso
}

The communitarian therapy as a new instrument of care for elderly mental health

La terapia comunitaria como un nuevo instrumento de cuidado para la salud mental del anciano

\author{
lanine Alves da Rocha', Lucineide Alves Vieira Braga', Lucídia de Medeiros Tavares', \\ Fábia Barbosa de Andrade', Maria de Oliveira Ferreira Filha', Maria Djair Dias', Antônia Oliveira Silva' \\ 'Universidade Federal da Paraíba. Programa de Pós-Graduação em Enfermagem, \\ Grupo de Estudos e Pesquisa em Saúde e Sociedade. João Pessoa, PB
}

Submissão: 04/05/2009

Aprovação: $31 / 08 / 2009$

\section{RESUMO}

A Terapia Comunitária vem surgindo como uma nova tecnologia de cuidado nos programas de inserção e apoio à saúde mental da população. Esta pesquisa exploratória tem como objetivo identificar o número de grupos de terapia comunitária com idosos no município de João Pessoa - PB, conhecer os principais temas apresentados pelos idosos e as estratégias utilizadas para o enfrentamento das dificuldades e revelar depoimentos relacionados à melhoria da Qualidade de vida dos idosos. Os dados foram coletados nas fichas de registro das terapias, analisado numa abordagem Quantitativa. Os resultados demonstraram que o problema mais freqüente nos idoso é o estresse, a estratégia de enfrentamento mais utilizada é a espiritualidade. A Terapia Comunitária vem contribuindo para saúde mental do idoso.

Descritores: Enfermagem; Saúde mental; Idoso; Terapia; Relações comunidade-instituição.

\begin{abstract}
The Communitarian Therapy comes appearing as a new technology of care in the programs of insertion and support to the mental health of the population. This exploratory research aims to identify the number of groups of community care with older people in the city of João Pessoa - PB, to know the main themes presented by the elderly and the strategies used to confront the difficulties and disclose evidence related to improving Quality of life of older people. The data had been collected in the fiches of register of the therapies, analyzed in a Quantitative boarding. The results had demonstrated that the problem most frequent in the aged one is stress it, the used strategy of confrontation more are the spirituality. The Communitarian Therapy comes contributing for mental health of the aged one.
\end{abstract}

Descriptors: Nursing; Mental health, Elderly; Therapy; Community-institutional relations.

\section{RESUMEN}

La Terapia Comunitaria viene surgiendo como una nueva tecnología de cuidado en los programas de inserción y apoyo a la salud mental de la población como un todo. Esta investigación de carácter exploratorio tiene como objetivos: identificar el número de grupos de terapia comunitaria con ancianos en el municipio de João Pessoa, Paraíba, Brasil, conocer los principales temas Que presentan los ancianos, así como las estrategias utilizadas para el enfrentamiento de las dificultades revelando las expresiones verbales relativas a la mejoría de la calidad de vida de los ancianos. Los datos fueron levantados en fichas de registro de las terapias, y analizados desde una perspectiva de abordaje cuantitativa. Los resultados demostraron Que el problema más frecuente en los ancianos es el estrés, y la estrategia de enfrentamiento más utilizada es la espiritualidad. La Terapia Comunitaria viene contribuyendo para la mejora de la salud mental del anciano.

Descriprores: Enfermería; Salud mental; Anciano; Terapia; Relaciones comunidad-institución. 


\section{CONSIDERAÇÕES INICIAIS}

A velhice é considerada a terceira idade da vida humana Que biologicamente é a etapa caracterizada pela Queda de força e degeneração do organismo. Mas há também implicações sociais e psicológicas Que influenciam no desenrolar da velhice e Que raramente são levadas em consideração ${ }^{(1)}$.

Apesar de ser menos preciso, o critério cronológico é um dos mais utilizados para estabelecer o ser idoso, até para delimitar a população de um determinado estudo ou para análise epidemiológica, ou com propósitos administrativos e legais voltados para desenho de políticas públicas e para o planejamento ou oferta de serviços. Costuma-se dizer Que a idade determinante da velhice é 65 anos, Quando se finaliza a fase economicamente ativa da pessoa e tem inicio a aposentadoria. Contudo, o ser idoso não pode ser definido só pelo plano cronológico, pois outras condições, tais como físicas, funcionais, mentais e de saúde, podem influenciar diretamente na determinação de Quem seja idoso ${ }^{(2)}$.

Outro critério muito utilizado para caracterizar alguém como idoso é o registro corporal, Que fornece características como: cabelos brancos, calvície, rugas, diminuição dos reflexos, compressão da coluna vertebral, enrijecimento e tantos outros. No entanto estas características podem estar presentes em pessoas Que não são consideradas idosas do ponto de vista da idade e mesmo que a pessoa já tenha a idade avançada, é possível mascararse a idade através de cirurgias plásticas, uso de cremes e ginásticas específicas. Torna-se então difícil determinar a velhice pelas alterações corporais ${ }^{(3)}$.

Alguns autores ${ }^{(4)}$ observam Que as mudanças determinantes de Quem é idoso, na maioria das vezes, são consideradas com referência às restritas modificações Que ocorrem no corpo, na dimensão física. Contudo é necessário Que se perceba Que, ao longo dos anos, são processadas mudanças também na forma de pensar, de sentir e de agir dos seres humanos Que passam por esta etapa do processo do viver. Acrescenta ainda Que o ser humano precise ser percebido como um ser complexo por ter várias dimensões: biológica, psicológica, social, espiritual e outras; Que necessitam serem consideradas para aproximação de um conceito.

Considerando o processo do envelhecimento como algo natural e irreversível ao Qual todos os seres humanos estão predestinados, se faz necessário uma reflexão sobre o mesmo, para Que no dia a dia se possam atender as necessidades da velhice. Tais necessidades são muito diversas e crescentes especialmente em um país como o Brasil, cujo aumento da população de idosos está em franca ascensão.

Conforme constatado pelo IBGE, em 2007 a população idosa brasileira era em média 18 milhões $(8,6 \%)$, nos últimos relatórios constam Que a mesma está em torno de 20 milhões de pessoas com 60 anos ou mais, perfazendo $10,5 \%$ da população total do Brasil, representando mais Que o dobro do crescimento da população total. Enquanto a população brasileira apresentou, no período de 1997 a 2007, um crescimento relativo da ordem de $21,6 \%$, para a faixa etária de 60 anos, este crescimento foi de $47,8 \%$ para mesma faixa etária, chegando a $65 \%$, no grupo de idosos de 80 anos ou mais ${ }^{(5)}$.

Diante deste crescimento percebe-se Que, de uma maneira geral, o idoso não possui subsídios financeiros e estruturais para manter uma boa Qualidade de vida. Em nossa cultura parece ser vergonhoso ser velho, visto Que usamos tantos artifícios para esconder a idade, disfarçando as marcas e sinais Que nos aproximam da condição indesejada. O preconceito de idade caracteriza-se por um processo de marginalização em Que as necessidades e os interesses dos idosos recebem menos atenção do Que a dos jovens; refletindo uma tendência de associar indevidamente a velhice a algo negativo e não como uma fase da vida Que tem aspectos positivos e negativos ${ }^{(6)}$.

No contexto de debate pelas condições do idoso, culminado pelo interesse cada vez maior em ampliar o conhecimento cientifico sobre a velhice e o envelhecimento, é Que se teve a atenção voltada dos cientistas sociais, médicos e trabalhadores de saúde mental, para Que não se adie simplesmente o envelhecimento, mas Que se prolongue a vida com Qualidade, considerando sempre os cuidados com a saúde mental dos idosos.

Entende-se Que envelhecer de maneira saudável e manter o bemestar na velhice significa ter saúde num sentido mais amplo; seria o equilíbrio entre um bom estado de saúde física somado aos sentimentos de respeito, segurança, oportunidade de participar da sociedade de acordo com suas limitações e posteriormente ser reconhecido pela sua contribuição. Logo se torna propício Que as políticas de saúde invistam em programas para incentivar a população estimando a redução dos índices de abandono, bem como problemas sociais vivenciados pelos idosos.

Neste sentido são criados serviços para acolher as pessoas que vivenciam a terceira idade na tentativa de atender algumas necessidades dessa faixa etária, além de oferecer uma oportunidade para Que elas possam sair da condição de isolamento estabelecendo vínculos com pessoas diferentes, aumentando e fortalecendo as suas relações pessoais.

Assim a Terapia Comunitária (TC) surgi como uma ferramenta de cuidado nos programas de inserção e apoio à saúde mental da população. A TC é um espaço de acolhimento, para a partilha de sofrimentos e sabedoria de vida, Que ocorre de maneira circular e horizontal. Constitui um espaço de escuta, reflexão e troca de experiências, criando uma teia de relação social entre os participantes, na busca de soluções para os conflitos pessoais e familiares ${ }^{(7)}$. Beneficia as relações interpessoais, a formação de redes sociais solidárias e a utilização da cultura popular como subsídio para soluções de problemas vividos pela comunidade.

A Terapia Comunitária foi desenvolvida a partir de 1987 na comunidade do Pirambu, em Fortaleza-CE, pelo Prof. Dr. Adalberto Barreto, docente do Curso de Medicina Social da Universidade Federal do Ceará, psiquiatra, teólogo e antropólogo, visando atender às necessidades de saúde de tal comunidade ${ }^{(8)}$.

Na Paraíba os profissionais do Programa de Saúde da Família preocupados com a saúde dos idosos têm desenvolvido grupos Que possam melhorar os vínculos sociais entre equipe e moradores, para ajudar a entender as principais preocupações relacionadas à saúde, conflitos familiares e emocionais. Nesse sentido, em João Pessoa - PB alguns profissionais vêm sendo capacitados em Terapia Comunitária com o propósito de auxiliar a comunidade no enfrentamento de suas preocupações do dia-a-dia.

A Terapia Comunitária aparece como uma tecnologia de cuidado, Que tem dado respostas satisfatórias aos Que dela se beneficiam, sendo mais um instrumento de trabalho, Que pode ser utilizado pelos profissionais da saúde, no cuidado com pessoas na 
comunidade ${ }^{(9)}$.

Diante de uma tecnologia de escuta e acolhimento, Que não traz maiores custos aos gestores, é válido ressaltar Que através desses encontros, os profissionais de saúde envolvidos na promoção da saúde mental, podem compreender melhor as preocupações e dificuldades da comunidade e direcionar suas condutas terapêuticas, melhorando a Qualidade de vida da população de idosos.

Partindo deste contexto, e com a vontade de contribuir para os conhecimentos da Enfermagem, bem como para firmação da Terapia Comunitária como prática efetiva do SUS, na tentativa de minimizar os transtornos mentais, em especial dos idosos, foram traçados os seguintes objetivos: Identificar o número de grupos de TC com idosos no município de João Pessoa - PB, desenvolvidos por terapeutas em formação da Estratégia de Saúde da Família; Conhecer os principais temas apresentados pelos idosos e as suas estratégias utilizadas no enfrentamento das dificuldades, relatadas nas rodas de terapias comunitárias; Revelar os depoimentos significativos dos idosos, considerando a vivência na terapia.

\section{METODOLOGIA}

Trata-se de ume estudo exploratório, pois desvendou aspectos da realidade pouco conhecida. Tal peseuisa identificou grupos de TC com idosos no município de João Pessoa - PB, coordenados por terapeutas em formação das ESF; enumerou os principais problemas relatados pelos idosos e as estratégias por eles utilizadas no seu enfrentamento, conforme relatados durante as terapias comunitárias; e revelou os depoimentos significativos dos idosos, relacionados à melhoria da Qualidade de vida.

O estudo foi realizado na Secretaria de Saúde do município de João Pessoa - PB, onde existe um banco de dados sobre as terapias realizadas pelos terapeutas em formação das ESF. Foi utilizado para esse estudo registros dos terapeutas com recortes de falas dos idosos que contribuíram durante os encontros da TC.

A coleta dos dados foi feita nas Fichas de Organização das Informações da T.C. Que foram utilizadas nos encontro de Terapia Comunitária, do município de João Pessoa - PB, Que ocorreram de Janeiro a Dezembro de 2007, por 60 terapeutas em formação, dos Quais apenas 40 desenvolveram pelo menos uma terapia com idosos. Na coleta de dados Que ocorreu no mês de julho de 2008 , foram consultadas 89 fichas Que registraram $75 \%$ ou mais de participantes idosos e Que tiveram origem deles o tema escolhido para contextualização e problematização da terapia.

Os dados Quantitativos foram organizados em um banco de dados para análise, com suporte do programa Microsoft Word versão 2007, onde as informações foram descritas na forma de variáveis e analisadas através da estatística descritiva com a inclusão dos resultados em tabela. Os dados Qualitativos foram apresentados de maneira discursiva, com enfoQue na compreensão e interpretação à luz da literatura pertinente.

A pesquisa foi aprovada pelo Comitê de Ética em Pesquisa, do Centro de Ciências da Saúde da Universidade Federal da Paraíba $\mathrm{CEP} / \mathrm{CCS}$, registrado sob protocolo $\mathrm{n}^{\mathrm{O}} 0197$ e consideramos as observâncias éticas preconizadas na Resolução 196/96 do Conselho Nacional de Saúde (CNS), Que dispõe sobre pesquisa em seres humanos no país.

\section{RESULTADOS E DISCUSSÃO}

\section{A Terapia Comunitária com grupos de idosos}

$\mathrm{Na}$ Estratégia de Saúde da Família, em geral os grupos de idosos são aQueles mais freqüentes nas comunidades, portanto eles acabam sendo também os participantes mais presentes nas rodas de TC.

Nesse cenário o resultado encontrado mostra Que não há dados informando o número absoluto de grupos, mas Que $70 \%$ dos grupos formados são de idosos, distribuídos entre as comunidades do município onde as rodas de terapia se desenvolvem.

Os grupos de idosos da TC têm como perfil de seus participantes a idade maior de 60 anos; sendo predominantemente sexo feminino; maior parte deles moradores de comunidades carentes e de difícil acesso a centros Que desenvolvam algum trabalho alternativo para idosos. Desse modo é comum a manifestação de problemas Que revelam o sofrimento da mulher na terceira idade, como insatisfação no casamento; alcoolismo do marido, violência do marido e filhos; problemas familiares; abandono do marido; sobrecarga de atividades doméstica; desvalorização pessoal; situações de preconceito pela idade, principalmente Quando a idosa é de cor negra; abandono dos filhos; baixa auto-estima; entre outros.

Além desses problemas são freqüentes aqueles de origem conjuntural de comunidades periféricas, como marginalização dos entes familiares mais novos pela falta de emprego e apoio aos estudos; renda financeira precária, onde muitas vezes o único sustento da família é fundamentado na aposentadoria dos idosos; difícil acesso aos serviços de saúde; precariedade no sistema de segurança; drogadição, etc.

A formação desses grupos instiga o indivíduo a interagir com outras pessoas e a descobrir no grupo a importância do outro na resolução dos problemas. Excita também a desvendar o poder resiliente em cada participante, bem como o comunitário.

Segundo alguns autores "resiliência é a capacidade de enfrentar adequadamente as dificuldades de forma socialmente aceitável”, e o objetivo dela "é ajudar os indivíduos e grupos não só a enfrentar as adversidades, como também a se beneficiar das experiências"(8). Para o mesmo autor, o enfoque em programas resilientes representa uma mudança de paradigma Que inclui a passagem do modelo médico tradicional centrado na fraqueza e na doença, para outra perspectiva Que inclui também a capacidade de enfrentamento, o estimulo às potencialidades, a consideração da esperança, como componente indispensável no desenvolvimento das pessoas.

Sabendo da importância desses grupos para a descoberta do poder resiliente individual e comunitário, e tendo em mente o crescente aumento da população idosa no Brasil é válida a implementação de programas de resiliência, para Que se possa estar inserido no contexto social do idoso, apoiando-os frente a situações sofredoras levando em consideração seus conhecimentos prévios os Quais são fontes de saber; minimizando assim a probabilidade de estigma social.

Rodas de TC: temas e estratégias apresentados pelos idosos

De acordo com as fichas de registro os principais temas apresentados pela população em estudo forma agrupados por categoria para avaliar o impacto da TC proposto pelo autor ${ }^{(6)}$ (Quadro 1.) Tal instrumento divide os temas por categorias, são 


\begin{tabular}{|c|c|c|c|}
\hline Tema & Sub-Tema & $\mathrm{N}$ & Origem/Causa \\
\hline \multirow[t]{4}{*}{ Conflitos Familiares } & Pais/filhos & 6 & Desrespeito \\
\hline & Esposo & 5 & Desvalorização pessoal \\
\hline & Avós/netos & 3 & Sobrecarga de cuidados \\
\hline & Irmãos & 1 & - \\
\hline \multirow[t]{4}{*}{ Alcoolismo } & Esposo & 5 & Vício \\
\hline & Filho & 3 & Ociosidade \\
\hline & Próprio & 2 & - \\
\hline & Pai & 1 & - \\
\hline \multirow[t]{2}{*}{ Drogadição } & Prisão & 1 & - \\
\hline & Dependência & 1 & - \\
\hline \multirow[t]{6}{*}{ Estresse } & Medo & 5 & Morte, perda do cônjuge \\
\hline & Angústia & 6 & Preconceito \\
\hline & Insônia & 3 & - \\
\hline & Ansiedade & 1 & - \\
\hline & Mágoa & 1 & Lembranças passadas \\
\hline & Desprezo & 1 & - \\
\hline \multirow[t]{2}{*}{ Conflitos } & Habitação & 4 & Perda de casa \\
\hline & Vizinhos & 1 & Barulho \\
\hline \multirow[t]{4}{*}{ Abandono } & Família & 2 & Não poder mais ajudar em casa \\
\hline & Órgãos públicos & 2 & Setor saúde \\
\hline & Esposo & 1 & - \\
\hline & Filhos & 1 & - \\
\hline \multirow[t]{3}{*}{ Violência } & Assalto & 1 & - \\
\hline & Contra o homem & 1 & - \\
\hline & Contra a mulher & 1 & Filho/nora \\
\hline \multirow[t]{3}{*}{ Depressão/perda } & Perda de filho & 2 & Morte \\
\hline & Sentimento de culpa & 2 & Não pôde cuidar da mãe \\
\hline & Parente & 1 & - \\
\hline \multirow[t]{3}{*}{ Trabalho } & Desemprego & 4 & Marido \\
\hline & Dificuldade financeira & 2 & Própria \\
\hline & Insegurança & 1 & Marido \\
\hline Rejeição & Colega de trabalho & 1 & - \\
\hline Prostituição & Homossexualismo & 1 & Neto \\
\hline Deficiências Mentais & - & 0 & - \\
\hline Discriminação & Idade & 4 & Preconceito \\
\hline \multirow[t]{4}{*}{ Problemas de saúde } & Doença própria & 9 & Osteoporose \\
\hline & Doença do esposo & 3 & Doença terminal \\
\hline & Doença do filho & 2 & Hepatite \\
\hline & Doença do ente Querido & 1 & - \\
\hline \multirow[t]{2}{*}{ Outros } & Solidão & 4 & - \\
\hline & Partilha de alegria & 4 & Bodas de prata \\
\hline Total & & 96 & \\
\hline
\end{tabular}

Quadro 1. Distribuição dos principais temas encontrados relatados pelos idosos durante os encontros de Terapia Comunitária, conforme a classificação de Barreto. João Pessoa, agosto, 2008.

elas: I-conflitos familiares (com o esposo, pais e filhos, irmãos, avós e netos, etc); 2-alcoolismo (do filho, esposo, pai, próprio, etc.); 3-drogadição (prisão, tráfico, etc); 4-estresse (angústia, medo, ansiedade, insônia, magoa, desprezo, etc); 5-conflitos (de habitação, entre vizinhos, etc); 6-abandono_(de órgãos púbicos, do esposo, filho, família, etc); 7-violência (familiar, contra a mulher, assalto, etc.); 8-depressão/perda (perda de filho, parente, sentimento de culpa, etc.); 9-trabalho (desemprego, dificuldade financeira, insegurança, etc.); 10-rejeição (do colega de trabalho, etc); 1 Iprostituição; 12-deficiências mentais; 13-discriminação (cor, raça, doença, etc). Na categoria outros foram relacionados mais três temas: saúde (própria, mãe, pai, esposo, etc), solidão e partilha de alegrias. No encontro de TC é comum a contextualização de apenas um tema, porém no decorrer da análise das fichas, percebeu-se Que em alguns encontros havia o envolvimento de dois temas, dessa forma ambos foram considerados, o Que implicará no número de problemas apresentados (96) maior Que o número de encontros avaliados (89).

Conforme mostra Quadro 1, pode-se constatar Que o tema mais freqüente é o estresse. No sub-tema angústia os sentimentos que o indicaram estão relacionados a situações vivenciadas pelos idosos de desrespeito e menosprezo por causa de sua idade, retratando Que embora haja todo um incentivo na tentativa de inclusão dos idosos na sociedade por parte dos estudiosos, eles ainda continuam 
sendo alvo de piadas desrespeitosas e sofrendo por ser vítima de preconceito, descaso e discriminação. Também é necessário enfatizar que o idoso é muitas vezes negligenciado e desvalorizado pela própria família, a isso ainda temos Que somar a influência de Que a auto-imagem e alterações físicas decorrentes do envelhecimento contribuem para o aparecimento de um Quadro depressivo. Paralelo a isto se percebe em relatos escritos a insegurança e o medo por sentir-se desprotegido: "morro de medo de morrer sozinha"; "tenho medo de perder meu esposo"; essas falas são características do avanço da idade e nos mostram a fragilidade emocional em Que eles se encontram a carência de cuidado, de valorização, de atenção, de companhia e a necessidade de diálogo e afeto dentro de casa e/ou com os demais familiares. Esses sentimentos levam a perda de sono, a sensações depressivas e a se sentirem ansiosos, magoados e desprezados.

O declínio biológico normal no processo de envelhecimento e as dificuldades funcionais com o avançar da idade sustentam, de modo geral, uma concepção de velhice como período de decadência e improdutividade. Assim, alterações como as perdas sensoriais (déficits visuais e auditivos), os problemas ósteo-articulares, os déficits cognitivos, contribuem de modo considerável para o estreitamento da inserção social dos idosos, e são fatores Que interferem na autonomia e independência dos Que envelhecem, prejudicando a sua sociabilidade e bem estar, e também sendo fatores determinantes da incidência do estresse e desanimo na terceira idade. A falta da auto-estima geralmente presente resulta do descontentamento frente ao reconhecimento do estado de dependência, e também aparece como fator contribuinte para estresse e depressão no idoso ${ }^{(10)}$.

$\mathrm{Na}$ temática conflitos familiares, foi percebido que os atritos entre pais e filhos continuam a atingir os pais idosos mesmo depois da maturidade dos filhos; refletindo talvez à Quebra da estrutura $\mathrm{e}$ o respeito familiar. Os esposos continuam sendo alvos de preocupações, pois segundo dados das fichas, as mulheres idosas se sentem exploradas, desvalorizadas, temerosas a atos violentos dos companheiros ou com sobrecarga de trabalhos domésticos: "...me sinto sobrecarregada com os cuidados com meu esposo". Além disso, percebe-se maior incidência de conflitos familiares entre avós e netos, nora e sogra Quando há o retorno dos filhos casados para a morada dos pais. Essa situação, Que na maioria das vezes resulta do desemprego, faz com Que os idosos tenham responsabilidades de pais com os netos e a manutenção da casa fieue por conta da aposentadoria Que se torna insuficiente para o suprimento de duas famílias ou mais, levando-os ao endividamento e dificuldades financeiras. Nas falas percebe-se a preocupação das idosas com o desemprego de filhos e esposo:

"Meu filho não consegue arrumar um trabalho, e os bicos que ele faz não dá pra pagar o aluguel dele...";

"Meu marido tem dificuldade de arranjar emprego por causa da idade...".

Os últimos trinta anos foram marcados por alterações nos arranjos familiares por fatores diversas, tendo havido um aumento considerável de casos em que os avós passam a desempenhar o papel de pais, obtém sua custódia legal dos netos, oferecem cuidados diários e se responsabilizarem financeiramente por eles.
Nesse tipo de arranjo podem ser apontados benefícios e dificuldades conforme o Quadro em Que a família está inserida. Em alguns casos, pode haver uma divisão das responsabilidades, maior união entre os membros e aumento dos recursos familiares. Todavia, há casos em Que prevalecem os conflitos entre avós e pais Quanto à educação das crianças ou ainda descompromisso por parte dos pais e perda de privacidade. Tais conflitos e perdas aumentam o risco de depressão entre mães e avós(7).

No tocante a circunstância econômica familiar atual, as aposentadorias passaram a ser de fundamental importância para a renda da família por se tratar de um benefício regular e estável. Esse suporte financeiro faz com que menos membros da família trabalhem e o idoso se sinta sempre responsável pela manutenção do lar, mesmo Quando a idade não o permite mais. Assim cria-se o medo de não poder mais sustentar a família, o Que pode levar ao isolamento agravado pela marginalidade social e privações econômicas, fazendo do idoso um forte candidato à doença mental.

Sobre problemas de saúde, percebe-se que a doença física se faz cada vez mais presente com o avanço da idade contribuindo significativamente para o comprometimento mental do idoso, pois eleva os sentimentos de preocupação e fragilidade diante da resposta imunológica ineficaz, do difícil acesso aos serviços de saúde e medicamentos, somatizando-se e ampliando ainda mais a sensação de iminência de morte. Em geral, estes efeitos negativos do contexto social inapropriado para atender a necessidade idosa contribuem para exacerbar os problemas de saúde deles ${ }^{(10)}$.

O conhecimento desse fato nos faz perceber que estamos diante de uma problemática difícil, pois os clássicos modelos de promoção, prevenção e reabilitação proposta pelo Sistema Único de Saúde não podem ser simplesmente transferidos para os senis, sem Que haja uma adequação de acordo com as necessidades e prerrogativas legais do idoso. Entre os desafios a serem enfrentados, encontram-se a necessidade de melhor sistematização das informações, ampla divulgação e o seu uso para o planejamento de políticas voltadas para a saúde do idoso ${ }^{(3)}$. A assistência ao idoso requer pessoal Qualificado e multiprofissional, Que façam uso de tecnologias mais esclarecedoras.

\section{Principais estratégias utilizadas}

No total de 89 encontros houve o registro de 232 estratégias de enfrentamento, e todas elas foram avaliadas e alistadas nesse estudo (Quadro 2). As estratégias foram agrupadas por semelhanças à medida Que iam sendo mencionadas, são eles: I-espiritualidade (fé e oração); 2-diálogo; 3-apoio familiar; 4- grupos de apoio (AA, grupos da igreja, grupos de dança, grupos de revigoramento físico, grupos de ginástica); 5-apoio de amigos; 6-perdão; 7conformação (aceitar os problemas como forma de crescimento, ou compreendendo); 8-procurar órgãos públicos (polícia, secretaria de saúde, governos); 9-determinação (ter força de vontade para superação de problemas); 10-paciência (para ouvir, e agir com cautela); I 1-lazer (jogos, viagem, festas, músicas, leitura); 12trabalhos alternativos (vender doces, fazer trabalhos manuais, costurar, bijouterias); 13-procurar especialista (médicos, psicólogos, fisioterapeutas); 14-cultivar a auto-estima (arrumarse, valorizar-se, comprar roupas novas); 15-amar. Outras estratégias foram citadas, porém não alcançaram representação numérica considerável para serem discutidas nos resultados. 


\begin{tabular}{|lcc|}
\hline Estratégias & $\mathbf{n}$ & \% \\
\hline Perdão & 5 & 2,15 \\
Diálogo & 15 & 6,46 \\
Apoio familiar & 18 & 7,75 \\
Grupos de apoio & 16 & 6,89 \\
Apoio de amigos & 17 & 7,32 \\
Espiritualidade & 57 & 24,56 \\
Conformação & 16 & 6,89 \\
Procurar órgãos públicos & 3 & 1,29 \\
Determinação & 23 & 9,91 \\
Paciência & 10 & 4,31 \\
Lazer & 10 & 4,31 \\
Trabalhos alternativos & 11 & 4,74 \\
Procurar especialista & 15 & 6,46 \\
Cultivar a auto-estima & 6 & 2,58 \\
Amar & 3 & 1,29 \\
Vingar-se & 2 & 0,86 \\
Uso de fitoterápicos & 5 & 2,15 \\
TOTAL & 232 & 100,00 \\
\hline
\end{tabular}

\section{Quadro 2. Distribuição das estratégias de enfrentamento sugeridas durante os encontros de Terapia Comunitária entre idosos. João Pessoa, agosto, 2008.}

A estratégia mais utilizada foi o fortalecimento da espiritualidade com 57 citações (24,56\%), onde segundo relatos dos participantes é na oração e no cultivo a sentimentos de esperança movidos pelo desejo de conquista, Que eles encontram conforto: “...ore com fé Que deus Ihe ajuda". A fé vem ganhando cada vez mais credibilidade no conceito da biomedicina, pois vários foram os momentos em Que se percebeu o poder dela na cura, dessa forma "mantendo separadas as dimensões do corpo e da alma, é preciso não subestimar o risco das conseqüências de uma religiosidade"(15).

$\mathrm{Na}$ terapia comunitária reverenciam-se todas as possibilidades de cura e soluções, buscando sempre o fortalecimento de sentimentos propulsores da vida como esperança, determinação, fé, fazendo com Que cada um se conscientize Que é responsável por uma parte da solução de seus problemas.

A força de vontade e determinação foi a segunda estratégia mais indicada, com 23 relatos (9,91\%); instigando em cada participante a vontade própria de vencer os problemas, cultivando a perseverança e a coragem na luta, frente as dificuldades diárias.

A fala da capacidade do ser humano de transcender os limites, e Que Quando isso potencializa o ser humano, amplia sua liberdade, encoraja para enfrentar os desafios do dia-a-dia, tornando as pessoas mais compassivas e solidárias, então ela será boa para o ser humano ${ }^{(11)}$.

Em seguida o apoio familiar com 18 citações $(7,75 \%)$, é sugerido pelos participantes da TC como uma tática Que tem representação significativa na vida de todos, pois a família unida por laços sanguíneos e afetivos será sempre o alicerce da sociedade. A família constitui o maior recurso para enfrentar as situações estressantes da vida em comunidade, assumindo funções de estabilidade social para seus membros, proteção física e mental, educação e sentimentos de satisfação; tudo isso em resposta as necessidades da sociedade e adeQuação a uma cultura.

Quando o idoso não vive mais no convívio familiar, ocorre um rompimento do equilíbrio das funções provocando sentimentos de tristeza, desamparo, desprezo, solidão e abandono. Assim, pode-se dizer Que uma família afetuosa e interessada é benéfica na idade avançada ${ }^{(12)}$.

\section{Depoimentos revelados pelos idosos considerando a vivência na terapia}

É comum nos encontros de TC as pessoas relatarem momentos de superação de vida e o Que aprenderam na discussão de problemas semelhantes ao do tema escolhido. As experiências de vida caracterizam o poder resiliente de cada participante, fazendo reconhecer a contribuição dela para manutenção da saúde mental.

Resiliência é o processo Que excede o simples superar, já Que permite sair fortalecido de situações adversas, contribuindo necessariamente para saúde mental. Ela diminui a intensidade do estresse e de sinais emocionais negativos, como depressão, ansiedade, raiva; e sob condições e valores próprios lhes permite metabolizar o evento negativo e construir a partir dele. Um dos fatores da resiliência é o respeito pelos outros e por si mesmo, fazendo com Que ela seja positiva Quando alcança as expectativas sociais. Assim a capacidade resiliente permite tolerar, manipular $\mathrm{e}$ aliviar as conseqüências psicológicas, sendo efetiva não apenas para adversidades, mas para promoção da saúde mental e emocional; contribuindo dessa forma para Qualidade de $\operatorname{vida}^{(13)}$.

Tendo em vista Que a vivencia pessoal e o compartilhamento de sofrimentos são fontes de saber, as reflexões dos encontros de TC são necessárias porQue elas funcionam como mola propulsora para o processo de empoderamento e resiliência.

Nessa pesquisa várias falas comprovam o poder resiliente em cada participante e a contribuição Que a terapia comunitária vem dando para essa coneuista. Veja a seguir os discursos dos idosos ao término dos encontros de TC:

“...a terapia hoje me passou coragem e determinação para suportar meus problemas"; "Hoje tive a certeza de ter um grupo de apoio para ajudar a superar a dor...";

"Estou animada e com força para conseguir..."; " O acolhimento daQui me trás alegria..."; “...envelhecer é uma beleza”; 
"Encontrei uma outra família...";

"Tenho um banco de alegria...";

“Conheci Que sou responsável pela minha vida.”;

"A TC me faz muito bem, acho Que vou retornar outras vezes";

"Saber que sempre existe uma luz no final do túnel....";

"Reflexão sobre o trabalho e grupo...";

“vejo que tudo tem seu tempo...".

Através desses discursos é possível perceber a conotação positiva Que seus participantes têm dos encontros. A Terapia Comunitária parece-nos como um instrumento poderoso para instalar, ainda Que na duração de um encontro, a prática democrática onde todos se sentem iguais como viajantes de um mesmo barco cuja trajetória é definida pela competência e experiência de cada um, somada aos recursos e competências grupais ${ }^{(14)}$.

Desta forma, se torna fundamental a adoção de práticas Que auxiliem na promoção da socialização do idoso, aumentando o bem-estar físico e psicológico. A capacidade e a possibilidade de ajudar, de participar como sujeito ativo nas interações pode implicar em resultados positivos na saúde mental das pessoas idosas ${ }^{(6)}$.

\section{CONSIDERAÇÕES FINAIS}

Nesse estudo foi verificado que o problema mais freqüente nos idoso é o estresse, Que a estratégia de enfrentamento mais utilizada é o fortalecimento da espiritualidade, e que através dos discursos dos idosos registrados nas fichas é possível perceber os benefícios alcançados e as mudanças Que ocorreram em suas vidas após a participação nos encontros de TC. Encontrou-se, além disso, o perfil dos idosos participantes da TC, como sendo a idade maior de 60 anos, a maioria do sexo feminino e moradoras de comunidades carentes.

Os temas encontrados caracterizam a realidade local e acarretam insegurança e instabilidade sócio-afetiva numa fase da vida Que reQuer atenção e cuidados redobrados; além disso, a correlação entre eles nos remete a idéia de uma cascata de problemas Que podem surgir após o aparecimento de alguma dificuldade, potencializando o comprometimento mental. As estratégias de enfretamento desvendadas caracterizam o poder resiliente em cada participante e demonstram a importância do saber popular, fazendo valer a cultura local Que tem por essência o senso comum.

Esses achados permitiram conhecer a importância da Terapia Comunitária como tecnologia do cuidado, além de fomentar subsídios para ações humanizadas tendo em mente, Que é respeitando os aspectos culturais de cada indivíduo e levando em consideração seus conhecimentos e experiências prévias, as Quais são fontes do saber e base para a construção do conhecimento, Que minimizaremos a Questão do estigma social para com o idoso, tanto pela família/comunidade como também pelos profissionais da área de saúde.

Ao final dessa pesquisa entende-se a importância de profissionais Que pensam sobre a problemática da velhice e Que lutam em adotar atitudes Que possa atender às necessidades do idoso. Compreendese Que a população senil vem sofrendo os efeitos do mundo dominado pelo capitalismo, das relações familiares cada vez mais frágeis, do desemprego e da prostituição, de forma mais agressiva por não possuir o mesmo poder de adaptação Que os jovens.

Nesse sentido vale lembrar a importância para os idosos da formação de grupos de apoio em busca do fortalecimento da Resiliência e resgate da autonomia; da contribuição Que os profissionais podem dar, para reduzir o estigma social, com a adoção da TC como ferramenta para a descoberta de problemas relevantes Que os afetam; da divulgação de políticas voltadas para a saúde do idoso na família e sociedade; e da capacitação de cuidadores.

A velhice é para ser vivida com Qualidade, rodeada de respeito e segurança, incluída num contato social saudável e de conscientização política, Que contribuirá significativamente para a melhoria da saúde mental e diminuição do sofrimento emocional do idoso.

\section{REFERÊNCIAS}

1. Vieira MP. Velhice. Fonoaudiologia e saúde. [citado em 17 jan 2008]. Disponível em: http://www.fonoesaude.org/velhice.htm.

2. Santos SSC. A gerontologia à luz da complexidade de Edgar Morin. Rev Eletrônica Mestr Educ Ambient [Internet]. 2004. [citado em: 3 dez 2007]. Disponível em: http:// www.tede.ufsc.br

3. Rebouças M, Pereira MG. Indicadores de saúde para idosos: comparação entre o Brasil e os Estados Unidos. Rev Panam Salud Pública 2008.

4. Martins CRM. O envelhecer segundo adolescentes, adultos e idosos usuários do SESC Maringá: um estudo de Representações Sociais [dissertação]. Florianópolis: Universidade Federal de Santa Catarina; 2002.

5. Instituto Brasileiro de Geografia e Estatística. Síntese de Indicadores Sociais. Rio de Janeiro; 2004 [citado em 17 out 2008]. Disponível em: http://www.ibge.gov.br/home/ presidencia/noticias/noticia_visualiza.php?id_noticia $=$ I 233\&id_pagina $=1$.

6. Nogueira FNN, Moreira V. Do indesejável ao inevitável: a experiência vivida do estigma de envelhecer na contemporaneidade [dissertação]. Fortaleza: Universidade de Fortaleza; 2008.

7. Lopes ESL, Néri AL, Park MB. Ser avós ou ser pais: Os papéis dos avós na sociedade contemporânea. UnATI; 2005. [citado em 15 jul 2008. Disponível em: http://www.unati.uerj.br/tse/ scielo.php?script $=$ sci

8. Barreto A. Terapia Comunitária passo a passo. Fortaleza: Gráfica LCR; 2005.

9. Ferreira Filha MO, Dias MD. Terapia Comunitária: uma ação básica de saúde mental. Ioão Pessoa: Projeto de Extensão (PROBEX)/UFPB; 2006.

10. Pereira A. Envelhecimento, estresse e sociedade: uma visão psiconeuroendocrinológica. Ciências Cognição 2004.

I I. Boff L. Tempo de transcendência: o ser humano como um projeto infinito. Rio de Janeiro: Sextante; 2000. 
Rocha IA, et al.

12. Mancia IR, Portela VCC, Viecili R. A imagem dos acadêmicos de enfermagem acerca do próprio envelhecimento. Rev Bras Enferm 2008; 6 I (2): 22 I-6.

13. Melillo A. Resiliência: descobrindo fortalezas. Porto Alegre: Artmed; 2007.

14. Fukui L, Marchetti LB. Situações familiares em Terapia
Comunitária. In: $2^{\mathrm{a}}$ Jornada Paulista de Terapia Familiar 2003. São Paulo (SP), Brasil. [citado em 17 jul 2008]. Disponível em: http://www.abratecom.org.br/artigo_detalhe.asp? art_ID $=2$

15. Vasconcelos EM, Smeke ELM. A espiritualidade no trabalho em saúde. São Paulo: Hucitec; 2000 